\title{
Sistem Scoring Conversion TOEFL Paper Based Test (PBT) Politeknik Negeri Cilacap Menggunakan Metode User Centered Design
}

\author{
Cahya Vikasari ${ }^{\# 1}$ \\ \# Jurusan Teknik Informatika, Politeknik Negeri Cilacap \\ Jl.Dr. Soetomono.1 Sidakaya Cilacap Jawa Tengah \\ ${ }^{1}$ cvikasari@omail.com
}

\begin{abstract}
Abstrak - Sistem komputer interaktif untuk dipakai oleh user untuk mendukung pekerjannya. User merupakan object yang penting didalam pengembangan dan pembangun sistem. User adalah personal-personal yang terlibat langsung dalam pemakaian aplikasi. Konsep dari UCD adalah user sebagai pusat dari proses pengembangan sistem, dan tujuan/sifatsifat, konteks dan lingkungan sistem semua didasarkan dari pengalaman pengguna Pembangunan sistem skoring test TOEFL paper based test (PBT) di UPT bahasa politeknik negeri cilacap menggunakan metode UCD. Dengan menggunakan metode UCD sistem dapat mempermudah dan mempercepat pendaftaran oleh calon pendaftar dengan tampilan antarmuka yang user friendly, mempermudah proses pengelolaan data dan rekap data pendaftar, mempermudah pengkonversian skor TOEFL yang dilakukan secara otomatis, serta meminimalisir terjadinya kesalahan, duplikasi data dan duplikasi kegiatan.
\end{abstract}

Kata kunci - TOEFL, User, Sistem, Interaktif, Skoring

\section{PENDAHULUAN}

\section{A. Latar Belakang Masalah}

Salah satu Unit Pelaksana Teknis yang ada di Politeknik Negeri Cilacap yaitu UPT yang berperan aktif dalam program pelatihan bahasa dan program test kemampuan bahasa khususnya Bahasa Inggris. Kegiatan UPT Bahasa PNC adalah melakukan kegiatan TOEFL paper based test (PBT) serta administrasi data untuk menangani kegiatan yang berkaitan dengan tes TOEFL. Kegiatan administrasi UPT masih manual misalnya calon pendaftar harus datang langsung untuk mengisi formulir pendaftaran, kemudian direkap oleh admin dan dibuatkan kartu tes. Hal ini akan menimbulkan beberapa permasalahan dikarenakan peran admin yang merupakan dosen dengan tugas tambahan sebagai staff UTP Bahasa PNC bisa tidak maksimal karena proses administrasi masih dilakukan secara manual. Tugas utama sebagai dosen yaitu melakukan pengajaran, kegiatan pengabdian kepada masyarakat dan melakukan penelitian, jika kegiatan tridharma perguruan tinggi sedang dilaksanakan maka proses administrasi akan berjalan lambat serta calon peserta jika tidak bertemu dengan staff UPT Bahasa tidak bisa mendaftar.

Pengolahan data administrasi masih menggunakan microsoft office sehingga dapat terjadi duplikasi kegiatan, proses ini memungkinkan terjadinya kesalahan pada proses pengolahan data yang dimasukkan. Pada proses pencarian data pendaftar masih mengalami kesulitan karena harus mencari berkas satu per satu, hal ini menyebabkan waktu kerja menjadi lebih lama. Pengolahan data untuk penghitungan konversi nilai juga masih menggunakan microsoft excel dengan cara mengoreksi hasil dari test TOEFL kemudian mengkonversi nilai sesuai skor TOEFL internasional.

Diperlukan adanya sistem untuk meminimalisasi masalah diatas, diantaranya dengan membangun sistem informasi yang dapat menangani pengelolaan data administrasi yang ada di UPT Bahasa Politeknik Negeri Cilacap untuk meningkatkan tercapainya tertib administrasi dalam pelayanan mulai dari pendaftaran, pengolahan data pendaftar, proses rekap administrasi hingga penghitungan konversi nilai. Kemudahan peserta tes dan admin dalam menggunakan aplikasi dengan tampilan antar muka yang user friendly sehingga peserta test dapat melayani sendiri dalam proses pendaftaran,cetak kartu tes dan pengumuman hasil tes TOEFL.

Perancangan berbasis pengguna (User Centered Design) adalah istilah yang digunakan untuk menggambarkan filosofi perancangan. Konsep dari UCD adalah user sebagai pusat dari proses pengembangan sistem, dan tujuan/sifat-sifat, konteks dan lingkungan sistem semua didasarkan dari pengalaman pengguna[1]

Penelitian sebelumnya pernah dilakukan yaitu menitikberatkan interaksi dengan kios informasi pengalamannya menggunakan sistem lain. Tujuan merancang aplikasi kios informasi yang pada Rumah Sakit XYZ yang memberikan informasi-informasi yang berkaitan dengan Rumah Sakit menggunakan metode UCD[2]. Penelitian berikutnya membuat Business Placement Center yang membantu mengelola website alumni dalam memenuhi kebutuhan alumni salah satunya memberikan informasi mengenai lowongan pekerjaan. Website alumni sudah memberikan informasi mengenai lowongan pekerjaan. Penggunaan metode User Centered Design untuk mempermudah pengguna dalam menggunakan fasilitas yang ada pada website ketika mencari informasi lowongan pekerjaan dan pengguna berperan penting dalam setiap proses UCD[3]. Konsep user centered design dengan melakukan kustomisasi pada tampilan yang memudahkan user sebagai pengguna. 
Pembaharuan dari sistem sebelumnya selain menitikberatkan interaksi untuk mendapatkan informasi, sistem ini juga mampu mempermudah calon peserta tes TOEFL dapat melakukan self service yaitu proses pendaftaran, cetak kartu tes, dan melihat pengumuman hasil tes TOEFL. Sistem ini juga bukan hanya memberikan informasi tetapi memberikan kemudahan dalam pengelolaan administrasi oleh administrastor terutama dalam melakukan scoring hasil tes TOEFL yang akan dilakukan secara otomatis oleh sistem. Admin hanya memberikan koreksi jumlah benar kedalam sistem dan sistem otomatis akan melakukan konversi dan peserta test langsung dapat melihat pengumuman hasil tes TOEFL. Penggunan metode user centered design sangat diperlukan untuk memberikan kenyamanan kepada para pengguna dengan konsep aplikasi self service dalam sistem scoring conversion TOEFL paper based test (PBT).

\section{Metodologi PENELITIAN}

Dalam pembangunan sistem ini menggunakan konsep interaksi manusia dan komputer. Interaksi Manusia dan komputer merupakan komunikasi dua arah antara pengguna (user) dengan sistem komputer yang saling mendukung untuk mencapai suatu tujuan tertentu[7]. Pada penelitian ini juga dibutuhkan sebuah prinsip pengembangan dengan konsep user center design (UCD) yaitu [4]:

1. Fokus Pada Pengguna

Perancangan harus terkoneksi langsung dengan pengguna akhir atau calon pengguna melalui wawancara, survey dan workshop pada saat perancangan. Tujuannya adalah untuk memahami kognisi, karakter dan sikap pengguna serta karakteristik anthropometric. Aktifitas utamanya mencakup pengambilan data, analisis dan integrasinya kedalam informasi perancangan dari pengguna tentang karakteristik tugas, lingkungan teknis di dalam organisasi.

2. Pancangan Terintegrasi

Perancangan harus mencakup antar muka pengguna, sistem bantuan, dukungan teknis serta prosedur untuk instalasi dan pengaturan konfigurasi.

3. Dari Awal Berlanjut Pada Pengujian Pengguna pengguna harus mendapat kenyamanan yang sama sesuai dengan Satu-satunya pendekatan yang berhasil dalam perancangan sistem yang berpusat pada pengguna adalah secara empiris dibutuhkan observasi tentang kelakuan pengguna, evaluasi feed back yang cermat, wawasan pemecahan terhadap masalah yang ada, dan motivasi yang kuat untuk mengubah rancangan.

4. Perancangan Interaktif

Sistem yang sedang dikembangkan harus didefinisikan, dirancang, dan dites berulangkali. Berdasarkan hasil tes kelakuan dari fungsi, antarmuka, sistem bantuan, dokumentasi pengguna dan pendekatan dalam pelatihannya.
Ada empat proses dalam user centered design (UCD) yakni[6]:

1. Memahami dan menentukan konteks pengguna.

2. Menentukan kebutuhan pengguna dan organisasi.

3. Solusi perancangan yang dihasilkan.

4. Evaluasi perancangan terhadap kebutuhan pengguna. Secara detil proses dalam UCD dapat dilihat dalam Gambar 1 [5].

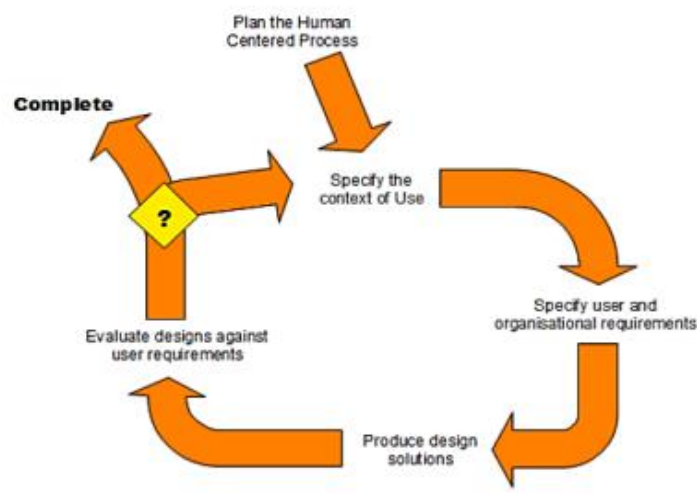

Gambar. 1 Proses dalam UCD

\section{A. Tahap Pengembangan Sistem}

Tahap penngembangan sistem ini menggunakan metode waterfall yang sering dinamakan siklus hidup klasik (classic life cycle), dimana hal ini menggambarkan pendekatan yang sistematis dan juga berurutan pada pengembangan perangkat lunak, dimulai dengan spesifikasi kebutuhan pengguna lalu berlanjut melalui tahapan-tahapan perencanaan (planning), permodelan (modeling), konstruksi (construction), serta penyerahan sistem ke para pelanggan/pengguna (deployment), yang diakhiri dengan dukungan pada perangkat lunak lengkap yang dihasilkan [6].

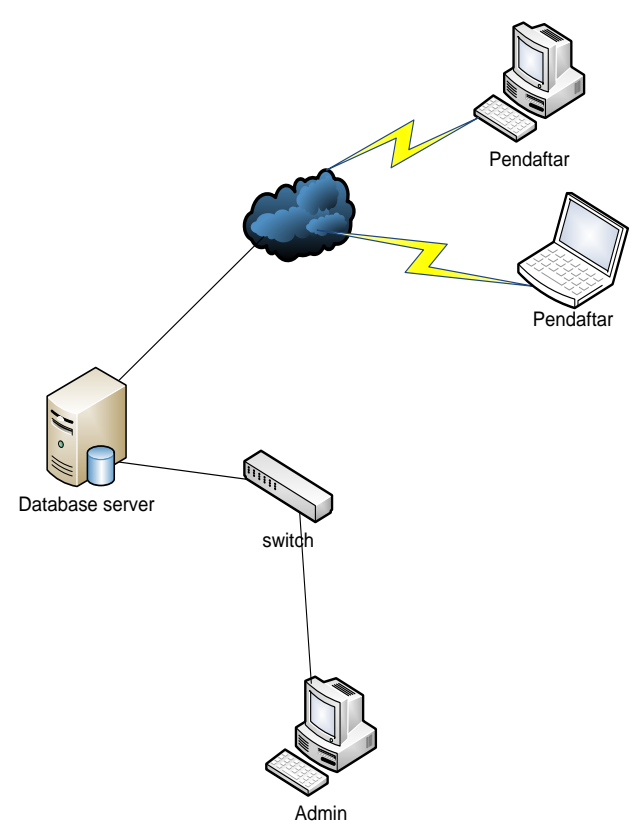

Gambar. 2 Kebutuhan Antarmuka Jaringan 


\section{Analisis Kebutuhan}

Proses Pengumpulan data dengan melakukan wawancara kepada pihak yang terkait di UPT Bahasa Politeknik Negeri Cilacap. Tahapan ini akan menghasilkan dokumen user requirement atau bisa dikatakan sebagai data yang berhubungan dengan keinginan user dalam pembuatan Sistem Skoring Test TOEFL paper based test (PBT) di UPT Bahasa Politeknik Negeri Cilacap.

Analisis kebutuhan antarmuka jaringan Sistem Skoring Test TOEFL paper based test (PBT) di UPT Bahasa Politeknik Negeri Cilacap. dapat dilihat pada Gambar 2.

\section{Perancangan}

use case diagram sistem scoring conversion TOEFL paper based test (PBT) di UPT Bahasa Politeknik Negeri Cilacap dapat dilihat pada Gambar 3. Pada gambar use case tersebut, ada dua aktor yang dapat menggunakan sistem yaitu pendaftar dan admin.

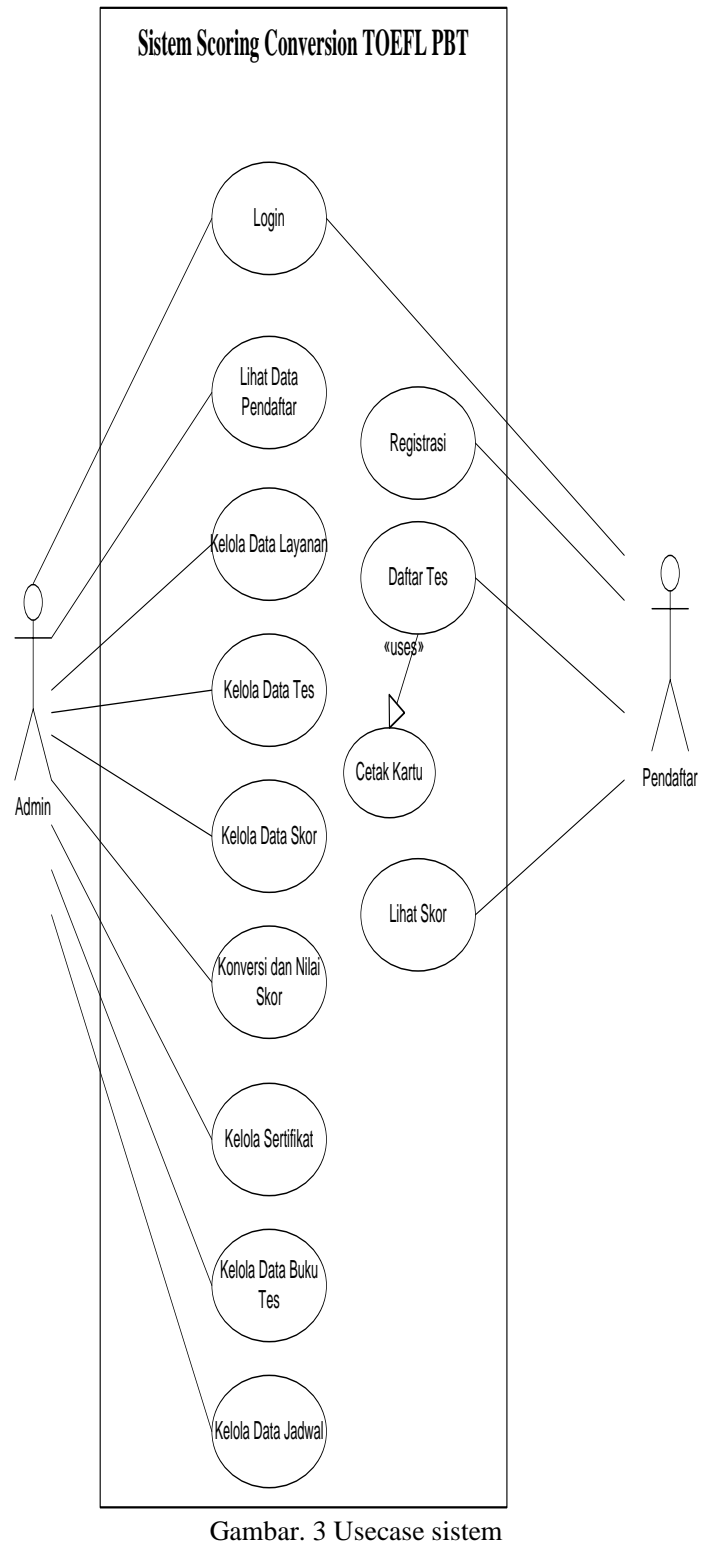

Entity Relationship Diagram yang digunakan untuk mengembangkan sistem scoring conversion TOEFL paper based test (PBT) di Politeknik Negeri Cilacap dapat dilihat pada Gambar 4.

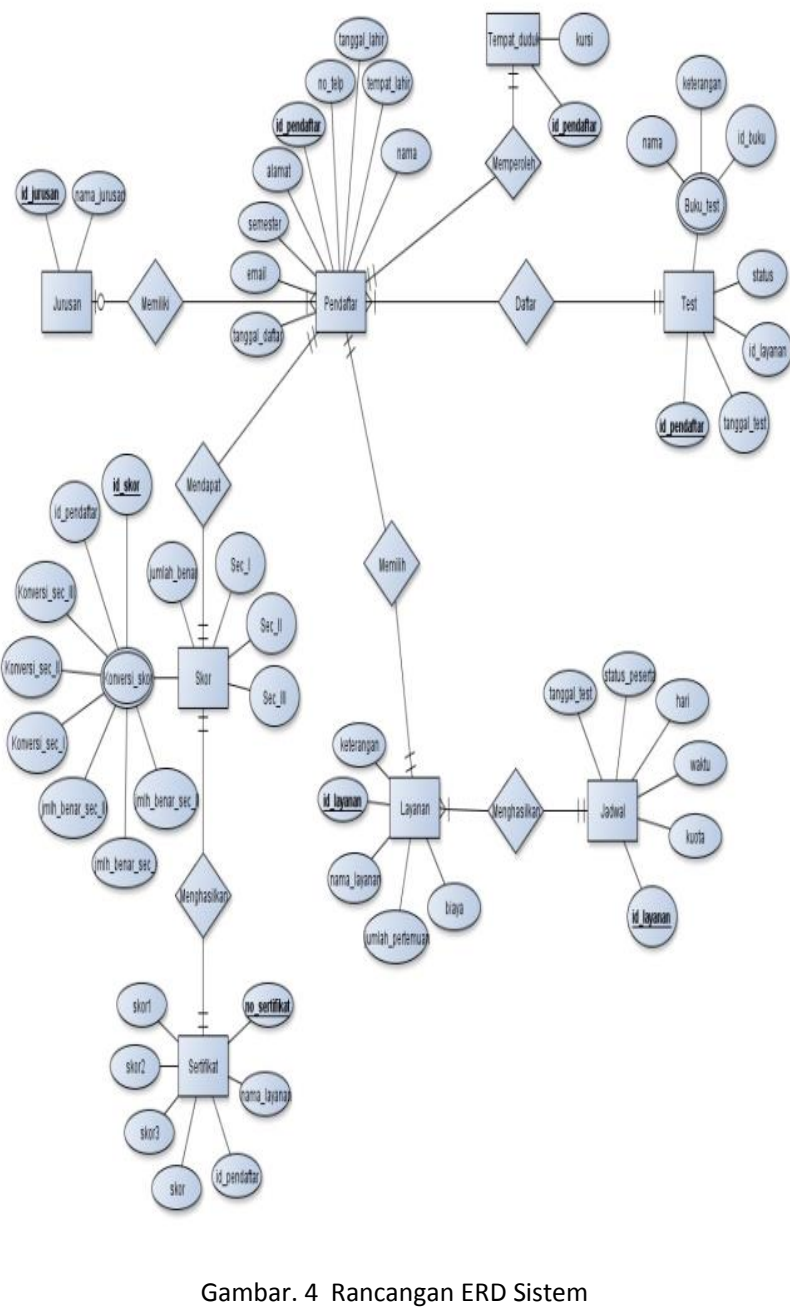

\section{HASIL DAN PEMBAHASAN}

Pada tahap ini adalah melakukan pembahasan langkah yang ada dalam proses UCD dengan implementasi tindakan dalam pembangunan sistem scoring conversion TOEFL paper based test (PBT) di UPT Bahasa Politeknik Negeri Cilacap :

1. Memahami dan Menentukan Konteks Pengguna (Specify the Context of Use)

Pengguna aplikasi sistem scoring conversion TOEFL paper based test (PBT) di UPT Bahasa Politeknik Negeri Cilacap ini adalah admin yang merupakan staff UPT Bahasa PNC dan pendaftar tes TOEFL. Aplikasi dibuat berbasis desktop untuk admin dan berbasis web yang dapat digunakan oleh pendaftar sehingga pendaftar dapat mengakses web dimanapun untuk melakukan registrasi, cetak kartu tes dan melihat hasil skor TOEFL yang diperolehnya. Sebagian besar pendaftar merupakan 
merupakan mahasiswa PNC yang mengambil tes TOEFL sebagai syarat wisuda di Politeknik Negeri Cilacap. Namun ada beberapa pendaftar dari kalangan umum dengan berbagai tujuan seperti syarat melamar kerja atau mendaftar pendidikan lebih lanjut. Pengguna aplikasi sistem scoring conversion TOEFL paper based test (PBT) mayoritas atau hampir seluruhnya dapat mengoperasikan komputer, hal ini akan mempermudah pengguna lebih cepat memahami aplikasi yang digunakan untuk mengelola tes TOEFL ini. Pendaftar dapat melihat jadwal pelaksanaan tesnya dan dapat langsung mencetak kartu tesnya. Dari sisi teknologi, sistem scoring conversion TOEFL paper based test (PBT) di UPT Bahasa Politeknik Negeri Cilacap yang dibangun berbasis web dan berbasis desktop, seta akan dihubungkan dalam satu basisdata yang akan disimpan dalam server sebagai pusat datanya.

2. Menentukan Kebutuhan Pengguna dan Organisasi (Specify User and Organitional Requirements)

Kebutuhan fungsional dari aplikasi sistem scoring conversion TOEFL paper based test (PBT) di Politeknik Negeri Cilacap sebagai berikut :

Pendaftar :

a. Dapat menggunakan aplikasi khususnya aplikasi berbasis web.

b. Melakukan pendaftaran.

c. Mencetak kartu tes dan lihat skor

Admin :

a. Mengelola data pendaftar

b. Mengelola data jurusan

c. Mengelola data layanan

d. Mengelola data jadwal

e. Mengelola tempat duduk

f. Mengelola buku test

g. Mengelola data test

h. Mengelola konversi skor

i. Mengelola sertifikat

3. Solusi Perancangan yang Dihasilkan (Produce Design Solutions)

Pada tahap ini akan dibuat perancangan yang sifatnya Iebih kongkrit yaitu dengan membangun sistem scoring conversion TOEFL paper based test (PBT). Pengguna aplikasi yaitu admin dan pendaftar dapat melihat dan mengamati saat aplikasi digunakan untuk menjalankan fungsi tertentu dan menggunakan umpan balik untuk melakukan tahap perbaikan terhadap rancangan sistem scoring conversion TOEFL paper based test (PBT).

\section{A. Menu Utama Web Pendaftar}

Tampilan antarmuka untuk pendaftar dibuat berbasis web agar mempermudah pengguna dapat mengakses halaman web dimanapun sehingga proses pendaftaran, cetak kartu dan lihat skor TOEFL dapat proses sendiri oleh pendaftar. Menu Utama untuk pendaftar berisi pendaftaran dan login untuk lihat skor. Tampilan menu pendaftar dibuat sederhana dengan ikon yang mudah dipahami oleh pendaftar. Tampilan Menu Utama pendaftar dapat dilihat pada Gambar 5.

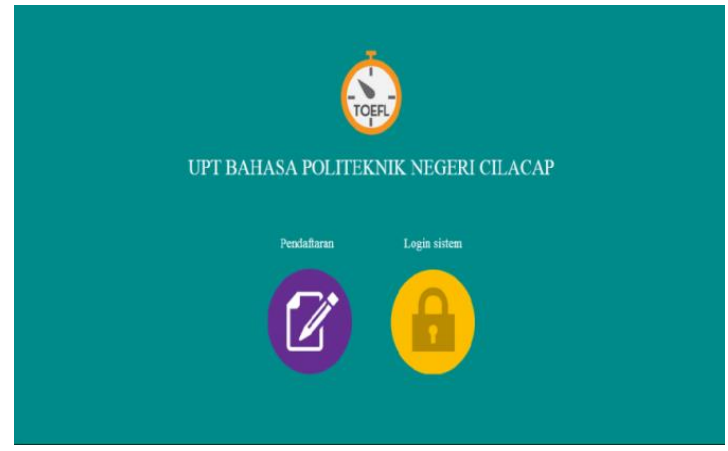

Gambar. 5 Implementasi Halaman Menu Utama Pendaftar

\section{A. Form Pendaftaran}

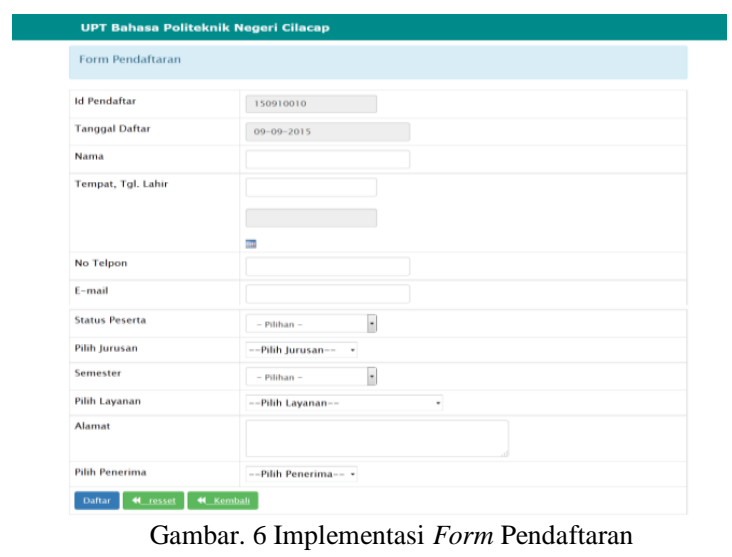

Form pendaftaran digunakan untuk melakukan pendaftaran secara online. Data yang diisi pada form pendaftaran dibuat dengan isian data diri yang mudah dijawab oleh pendaftar sehingga pengisian datanya dapat dilakukan dengan cepat walaupun jumlah data yang diperlukan banyak. Pada form tersebut terdapat tombol daftar berfungsi untuk menyimpan data baru yang telah diinputkan dan tombol reset berfungsi untuk membersihkan data yang dimasukan pada form pendaftaran.

\section{B. Tampil Skor}

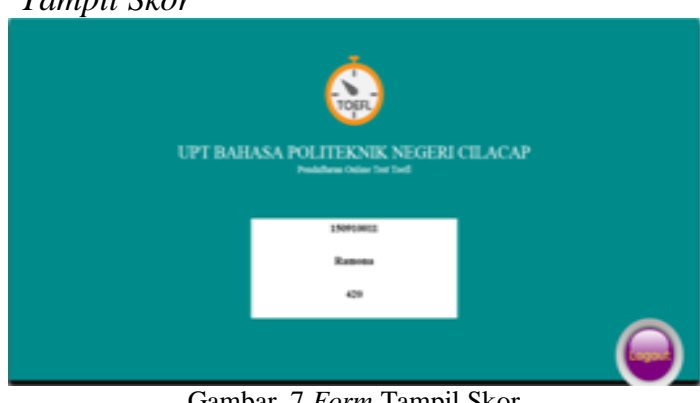

Tampil skor pendaftar digunakan untuk melihat skor yang sudah melakukan test. Pada tampilan lihat skor dibuat sederhana namun fokus pengamatan pendaftar langsung 
tertuju kepada hasil skor yang diperolehnya. Pada halaman tersebut terdapat tombol logout berfungsi untuk keluar dari form lihat skor.

\section{Form Login Admin}

Tampilan antarmuka admin dibuat berbasis desktop. Aplikasi diinstall di komputer UPT Bahasa, dengan membaca database yang disimpan di server sehingga data terpusat. Jika ada perubahan data oleh pendaftar melaui halaman web yang dapat diakses oleh pendaftar maka pada halaman aplikasi desktop yang diakes admin juga mendapat data perubahan secara uptodate Tampilan form login pada sistem dapat dilihat pada Gambar 8.

\section{LOGIN}

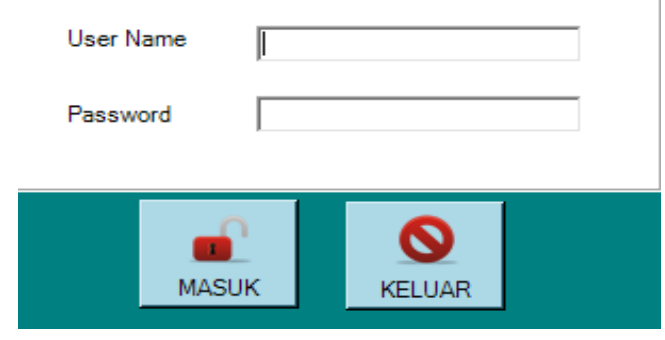

Gambar. 8 ImplementasiForm Login Admin

\section{Menu Utama Admin}

Menu utama untuk admin berisi beberapa pilihan yaitu file, pendaftar yang dapat digunakan untuk mengelola data pendaftaran dan melihan data pendaftar yang sudah masuk kedalam sistem, master yang akan digunakan untuk mengelola, data jurusan, data layanan, data jadwal, tempat duduk, buku tes, data tes, konversi skor, data sertifikat dan laporan. Tampilan halaman menu utama admin dapat dilihat pada Gambar 9.

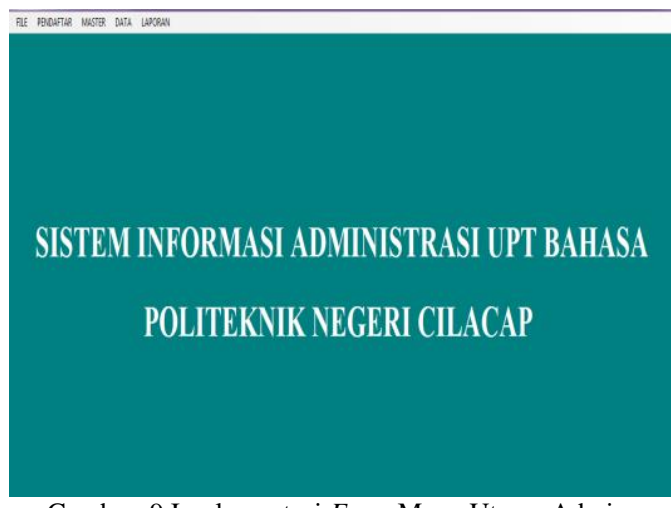

Gambar. 9 Implementasi Form Menu Utama Admin

\section{E. Form Layanan}

Form layanan digunakan untuk mengelola data layanan yang terkait, sistem dikelola oleh Admin. Pada form juga terdapat button simpan, hapus, refresh dan tutup. Form layanan untuk menyimpan data layanan yang ada di UPT
Bahasa seperti test TOEFL dengan berbagai jenis misalnya TOEFL preparation, TOEFL ITP, TOEFL EPT-P yang merupakan test TOEFL dengan konsep paper based test $(P B T)$. Tampilan form layanan dapat dilihat pada Gambar 10.

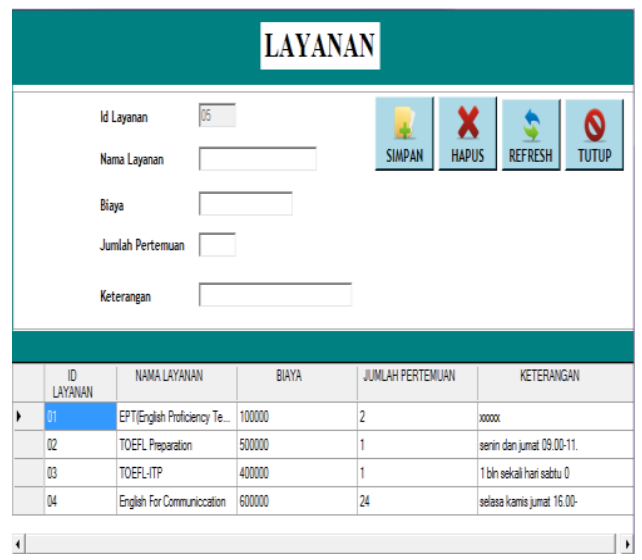

Gambar. 10 Implementasi Form Layanan

\section{F. Form Jurusan}

Form jurusan digunakan untuk mengelola data jurusan yang ada di Politeknik Negeri Cilacap, sistem dikelola oleh Admin. Pada form juga terdapat button simpan, hapus, refresh dan tutup. Button simpan berfungsi untuk menyimpan data yang telah diinputkan. Button hapus berfungsi untuk menghapus data yang di database. Button refresh berfungsi untuk merefresh data apabila tidak jadi menginputkan data. Button tutup berfungsi untuk keluar dariform jurusan. Tampilan form jurusan dapat dilihat pada Gambar 11.

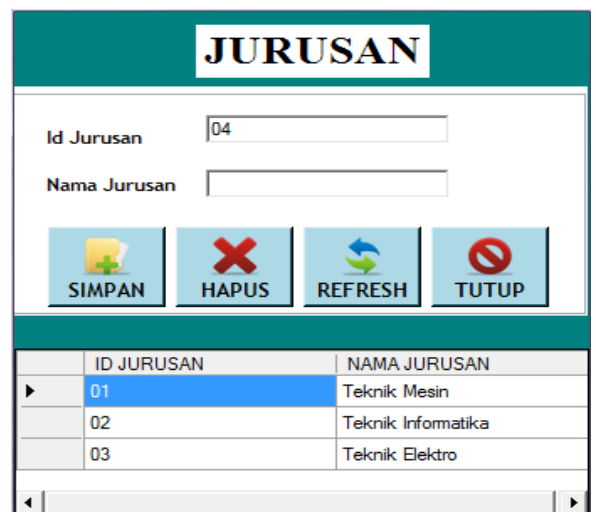

Gambar. 11 Implementasi Form Jurusan

\section{G. Form Jadwal}

Form jadwal digunakan untuk mengelola data jadwal utuk pelaksanaan kegiatan tes TOEFL. Jadwal tes dapat dibuat langsung pertahun sehingga ada data terjadwal untuk setiap sesi tesnya. Hal ini juga akan mempermudah bagian admin jika ada yang meminta informasi tentang pelaksanaan tes sehingga akan mempermudah dan mempercepat pelayanan admin. Tampilan form jadwal dapat dilihat pada Gambar 12. 


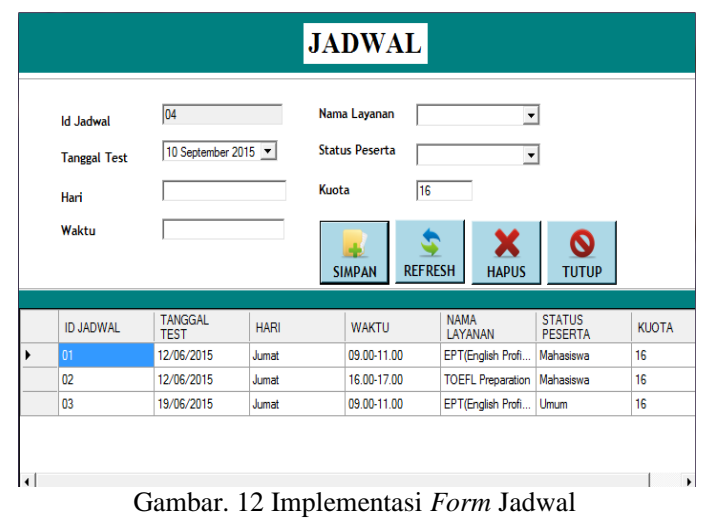

H. Form Skor

Form skor digunakan untuk mengelola data nilai skor yang terkait, sistem dikelola oleh Admin. Pada form juga terdapat button simpan, hapus, refresh dan tutup. Form skor diisi sesuai dengan ketentuan untuk yang ada. Tampilan form skor dapat dilihat pada Gambar 13.

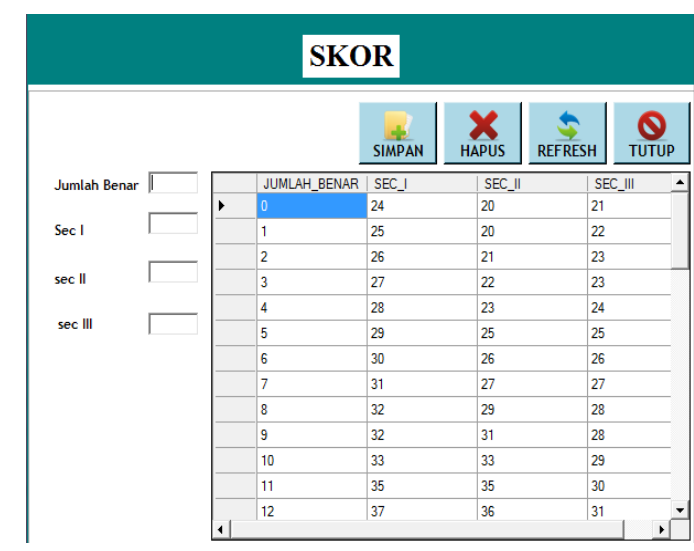

Gambar. 13 Implementasi Form Skor

\section{Form Buku Test}

Form buku test digunakan untuk mengelola data buku test yang terkait, sistem dikelola oleh Admin. Pada form juga terdapat button simpan, hapus, refresh dan tutup. Buku test berisi daa buku yang digunakan dalam pelaksanaan tes TOEFL. pengelolaan data buku test TOEFL diperlukan selain untuk mengetahui jenis buku tes yang dipunyai UPT Bahasa juga dapat digunakan untuk mengatur data buku yang akan dugunakan untuk setiap sesi tes TOEFL. Tampilan form buku test dapat dilihat pada Gambar 14.

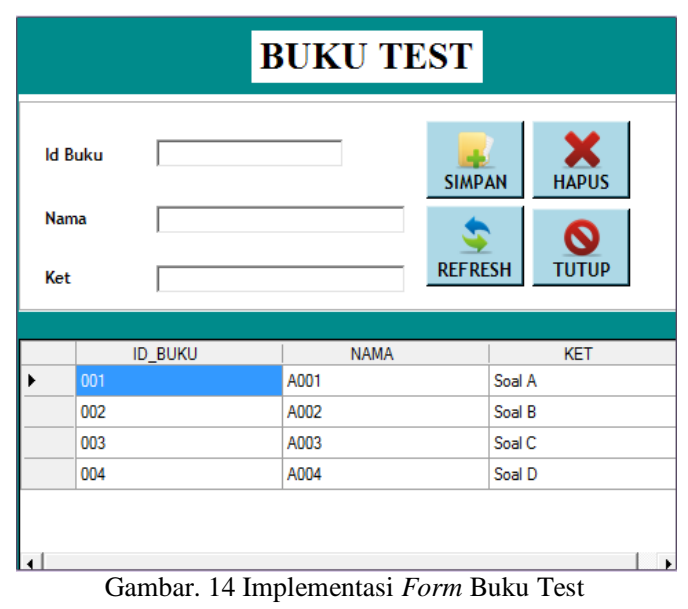

\section{J. Form Pendaftaran}

Form pendaftaran digunakan untuk mengelola data pendaftar. Sistem dikelola oleh Admin hal ini dimaksuskan jika ada pendaftar yang datang langsung ke UPT Bahasa admin juga dapat melakukan pengolahan data pendaftar. Tampilan form pendaftaran dapat dilihat pada Gambar 15.

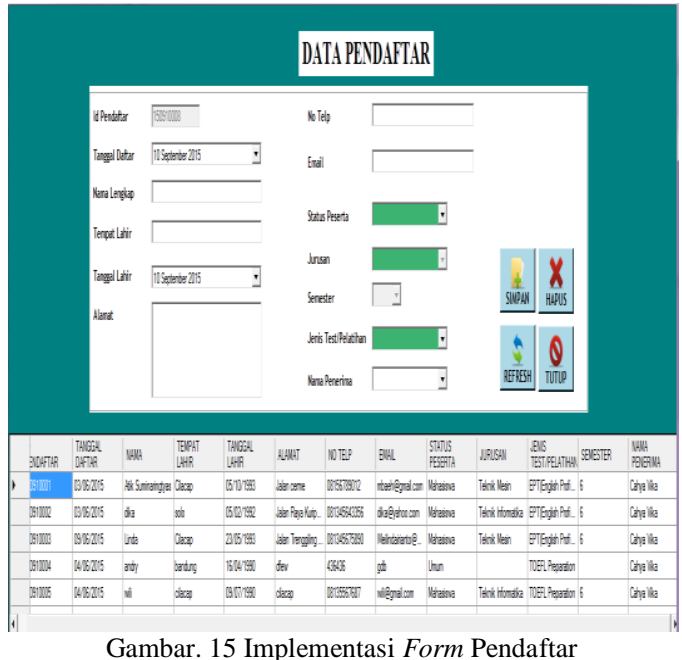

\section{K. Form Lihat Data Pendaftar}

Form lihat data pendaftar digunakan untuk melihat data pendaftar yang sudah mendaftar melalui sistem. Selain untuk pelaksanaan test data pendaftar juga diperlukan untuk marketing dan penawaran tes TOEFL, sistem dikelola oleh Admin. Pada form juga terdapat button cari agar admin mudah dan dapat untuk mencari data yang diperlukan dan refresh. Tampilan form lihat data pendaftar dapat dilihat pada Gambar 16. 


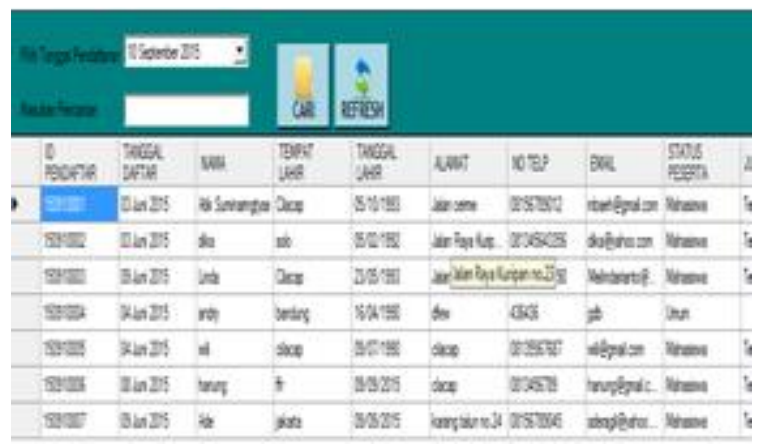

Gambar. 16 Implementasi Form Lihat Data Pendaftar

\section{Form Data Test}

Form data test digunakan untuk mengelola data tes yang akan dilaksanakan oleh UPT Bahasa Politeknik Negeri Cilacap. Data yang akan dikelola yaitu data layanan untuk setiap sesi tes, tanggal pelaksanaan, dan buku test yang akan dipakai dalam pelaksanaan tes. Tampilan form data test dapat dilihat pada Gambar 17.

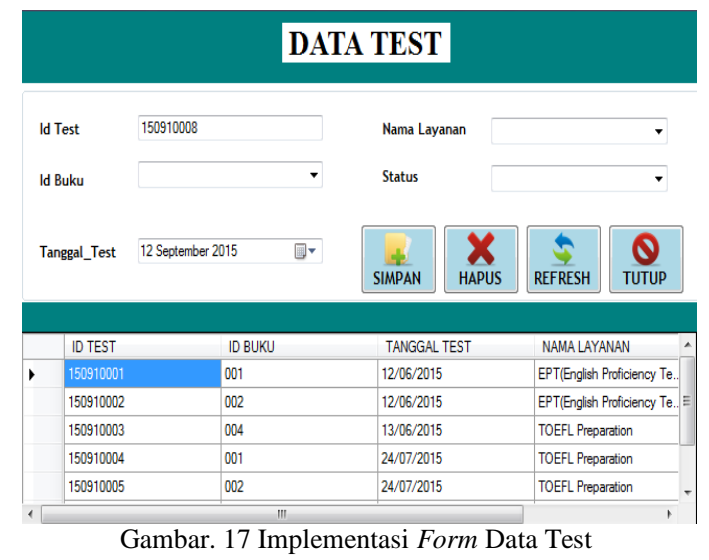

\section{Form Lihat Data Test}

Form lihat data test digunakan untuk melihat data test yang akan dlaksanakan oleh UPT Bahasa Politeknik Negeri Cilacap. Tampilan form lihat data test dapat dilihat pada Gambar 18.

\begin{tabular}{|c|c|c|c|c|c|}
\hline \multicolumn{4}{|c|}{ Cari Berdasarkan Tanggal Test 12 September 2015} & \multicolumn{2}{|c|}{ TAMPIL SEMUA } \\
\hline & $\begin{array}{l}\text { ID } \\
\text { PENDAFTAR }\end{array}$ & ID BUKU & $\begin{array}{l}\text { TANGGAL } \\
\text { TEST }\end{array}$ & NAMA LAYANAN & STAT \\
\hline \multirow[t]{7}{*}{ - } & 150910001 & 001 & 12/06/2015 & EPT(English Proficiency.. & BELUM \\
\hline & 150910002 & 002 & $12 / 06 / 2015$ & EPT(English Proficiency.. & BELUN \\
\hline & 150910003 & 004 & $13 / 06 / 2015$ & TOEFL Preparation & BELUM \\
\hline & 150910004 & 001 & $24 / 07 / 2015$ & TOEFL Preparation & BELUM \\
\hline & 150910005 & 002 & $24 / 07 / 2015$ & TOEFL Preparation & BELUM \\
\hline & 150910006 & 003 & $24 / 07 / 2015$ & TOEFL Preparation & BELUM \\
\hline & 150910007 & 004 & $24 / 07 / 2015$ & TOEFL Preparation & BELUN \\
\hline & 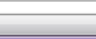 & & +2 & 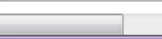 & 1 \\
\hline
\end{tabular}

Gambar. 18 Implementasi Lihat Data Test

\section{N. Form Konversi Skor}

Form konversi skor digunakan untuk mengelola skor TOEFL untuk masing-masing pendaftar. Admin mengisikan jumlah benar untuk masing-masing section dalam tes TOEFL, proses koreksi LJK akan dikerjakan dengan menggunakan scanner dan hasil dari koreksi sudah dapat langsung dimasukan kedalam sistem. Konversi hasil tes akan dilakukan secara otomatis oleh sistem tanpa membuat admin menghitung secara manual. Tampilan form konversi skor dapat dilihat pada Gambar 19.

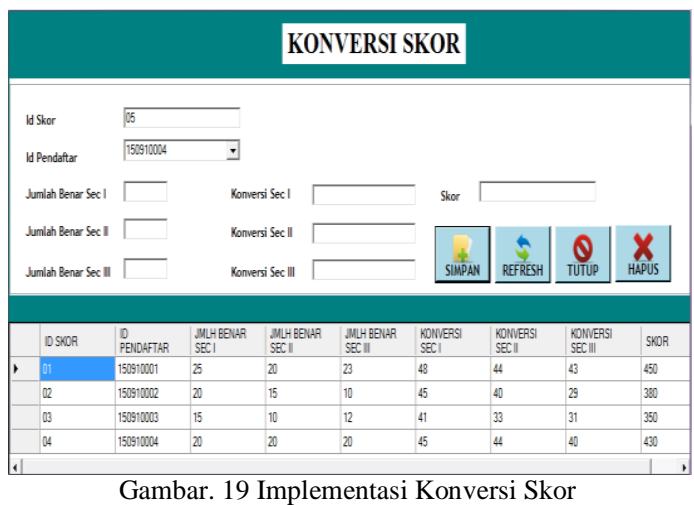

\section{O. From Sertifikat}

Form sertifikat digunakan untuk mengelola data sertifikat yang diperoleh para peserta test TOEFL. Pengelolaan sertifikat dilakukan oleh admin tata usaha Unit pelaksana teknis Bahasa Politeknik Negeri Cilacap. Tampilan form sertifikat dapat dilihat pada Gambar 20. Data yang dikelola pada form sertifikat sebagai acuan bagian tata usaha unit pelaksana teknis untuk memproses sertifikat TOEFL yang akan diberikan kepada peserta tes TOEFL.

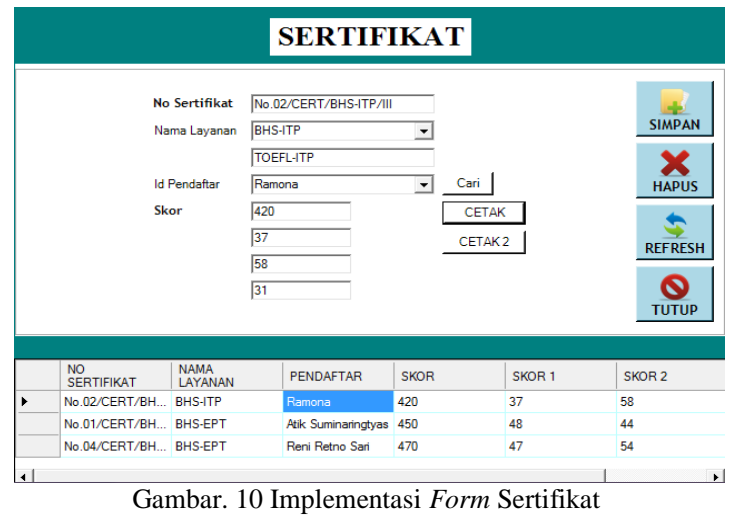

4. Evaluasi Perancangan Terhadap Kebutuhan Pengguna (Evaluate Design Againts User Requirement)

Tahap evaluasi perancangan terhadap kebutuhan pengguna merupakan tahap terakhir dalam proses user centered design (UCD). Fasilitas umpan balik diperlukan untuk memperbaiki rancangan (formative) yang ada, selain itu juga ada fungsi untuk melakukan penilaian apakah ada kesamaan tujuan pengguna dan organisasi telah tercapai dengan menggunakan sistem ini. Menu untuk admin untuk melakukan pengelolaan data administrasi kegiatan TOEFL dan melakukan perubahan data jika diperlukan. Aplikasi dibuat berbasis dektop untuk admin dan berbasis web untuk pendaftar. 


\section{PENUTUP}

Kesimpulan dan saran dari penelitian mengenai sistem scoring conversion TOEFL paper based test (PBT) adalah sebagai berikut :

\section{A. Kesimpulan}

1. Dengan menggunakan metode UCD maka sistem yang dihasilkan lebih memberikan kemudahan bagi pengguna dan meningkatkan kemanfaatan dari sistem karena sejak awal pengguna telah terlibat.

2. Faktor penentu keberhasilan pembangunan sistem dengan metode user centered design adalah membangun kedekatan yang harmonis antara pengembang sistem dengan user, sehingga diperoleh kebutuhan yang diharapkan oleh pengguna.

3. Sistem dapat mempermudah dan mempercepat pendaftaran oleh calon pendaftar dengan tampilan antarmuka yang user friendly, Mempermudah proses pengelolaan data dan rekap data pendaftar, mempermudah pengkonversian skor TOEFL yang dilakukan secara otomatis, serta meminimalisir terjadinya kesalahan, duplikasi data dan duplikasi kegiatan.

\section{B. Saran}

1. Penambahan dan pengoptimalan fitur -fitur yang ada dalam sistem dari user admin agar sistem benar-benar bisa digunakan, seperti sistem dapat melakukan cetak sertifikat secara otomatis.

2. Sistem dapat dikembangkan dengan teknologi sms gateway untuk kemudahan informasi.

\section{REFERENSI}

[1] 2010. User Centered Design (UCD)[online],available: http://ikydejan.blogspot.co.id/2010/08/user-centered-designucd.html.

[2] Wijang Widhiarso, Jessianti dan Sutini, Metode UCD (User Centered Design) Untuk Rancangan Kios Informasi Studi Kasus : Rumah Sakit Bersalin XYZ. Jurnal Ilmiah STMIK GI MDP,2007.vol.3

[3] Rhomita Sari , Ema Utami , ArmadyahAmborowati, Rancangan Lowongan Kerja Online Menggunakan Metode User Centered Design (Studi Kasus: Business Placement Center STMIK AMIKOM Yogyakarta). Citec Journal,2015.vol.3

[4] Amborowati, Armadyah, 2008. Rancangan Sistem Pameran Online Menggunakan Metode UCD (User Centered Learning). SNATS AKPRIND

[5] 2006. Proses UCD [online], available: http://www.upa.org.nz/wpcontent/uploads/2006/09/upanz-govis-sept-2006.pdf

[6] Pressman, Roger S. 2012. Rekayasa Perangkat Lunak-Buku Satu, Pendekatan Praktisi (Edisi 7). Yogyakarta: Andi.

[7] Santoso,Insap; Interaksi Manusia dan Komputer : Teori dan Praktek, Andi Offset, Yogyakarta, 2004. 